\title{
Perceptions of Staff Nurses about Patient Safety Culture at Minia General Hospital
}

\author{
Eman Sayed Hadad', Safaa Mohamed Abd Elrhmaan², Faten Ali Ahmad ${ }^{3}$, Heba Dakrory Ali ${ }^{3}$
}

1. B.Sc. of Nursing, Faculty of Nursing -Minia University

2. Professor of Nursing Administration, Faculty of Nursing -Minia University

3. Lecturer of Nursing Administration, Faculty of Nursing -Minia University

\begin{abstract}
Background: Since worries about not harming patients have gotten more attention in recent years, patient safety has become a key healthcare priority. Numerous studies have found that adverse outcomes are more likely to occur in general healthcare settings. Aim: the current aim is to assess perceptions of staff nurses about patient safety culture at Minia General Hospital. Research design: descriptive cross-sectional research design. Setting: The study was conducted in Minia General Hospital, at Minia city, Egypt. Subjects: convenience sample included all available staff nurses during data collection in Minia General Hospital (no=280). Tool of data collection: one tool was used Patient Safety Culture. Results: the study showed that the highest percentage of staff nurses have high total scores regarding patient safety culture for the dimensions "feedback and communication about error", "frequency of event reporting" "teamwork within units" and "organizational learning continuous improvement". Also, the study showed that the lowest dimensions from the staff nurses perception were for "supervisor $\backslash$ manager expectations and actions promoting patient safety"; "overall perceptions of patient safety" "staffing"; and "teamwork across hospital units". Conclusion: the results indicated that the overall perception of staff nurses regarding patient safety culture in the hospital were moderate. Recommendation: nurses should be encouraged to participate and foster the patient safety activities and communication channels in order to maintain safety regulation
\end{abstract}

Keywords: Culture, Perception, Patient, Safety, Staff Nurses

\section{Introduction}

Millions of patients suffer from illnesses, accidents, or death each year due to unsafe medical practices (Al- Lawati et al., 2019). Worldwide, it is estimated that 4 in 10 patients are harmed in primary and outpatient health care. In the developed countries, the number of patients harmed during hospitalization is estimated to be one in ten patients. Also, in low and middle-income countries (LMICs), each year, 134 million adverse events occur in hospitals due to unsafe care, resulting in 2.6 million deaths (World Health Organization, 2020).

A positive safety culture will improve a hospital's patient safety performance, which could help the organization strengthen its safety outcomes. A high level of safety control benefits physical and psychological health directly and positively. Furthermore, if the perception of safety control is high, negative consequences or reprisals for reporting safety issues will be reduced (El-Jardali et al., 2014).

Patient safety is defined as avoiding preventable harm to a patient during the health care process and reducing to an appropriate minimum risk of unintended harm that associated with health care (Al- Lawati et al., 2019). Also Patient safety is defined as the avoidance and prevention of patient injuries or adverse events resulting from the processes of health care delivery (Abdelrahman \& Mohamed, 2017). To prevent such harm, it is recommended from health care setting and health care providers to maintain and enhance the patient safety culture (Ammouri et al., 2015).

Attaining a safety culture requires an understanding of the values, attitudes, beliefs, and norms important to health care organizations and what attitudes and behaviors are appropriate and expected for patient safety (Ulrich \& Kear, 2014). Positive and robust patient safety cultures have significantly reduced the number of adverse events reported in a healthcare organization (DiCuccio, 2015).
Patient safety has become a major healthcare challenge since concerns about not harming patients have received increased attention in recent years. Numerous studies revealed that high chances exist of adverse events occurring in general healthcare environments (Graban \& Toussaint, 2018). The event is defined as any type of error, mistake, incident, accident, or deviation, regardless of whether or not it results in patient harm (Abdelrahman, Mohamed, 2017).

These unintended adverse events can lead to hospital admissions, a prolongation of hospital stays, increased medical expenditures, and the occurrence of serious permanent injury or death. Evidence from several studies suggested that these adverse events are often preventable, and are therefore manageable and avoidable (Cheng et al., 2019).

Therefore, establishment of a supportive patient safety culture in healthcare organizations is widely accepted and needed to be among the highest priorities for reducing adverse events and improving patient safety as well as quality of care. The safety climate generally refers to measurable components of safety culture. Assessment of the patient safety climate for healthcare workers is considered essential as a primary strategy to promote patient safety in organizations (Pousette et al., 2017).

Many factors can be associated with patient safety culture. Organizational culture that encourages reporting and avoids blame and improved communication are reported as important factors to improve patient safety culture. Elmontsri et al., (2017) showed that blame culture and poor communication were common factors associated with a low patient safety culture in Arab countries. Another review related to Almutairi et al., (2015) showed a communication issue between healthcare providers and patients, leading to preventable errors and low-quality care. This communication deficit was linked to language barriers, workforce diversity, and cultural differences. 
Other studies showed that patient safety culture can be influenced by respondent and hospital characteristics, work area, position, extent of participation in a patient safety program, communication, and patient safety management and resources. Inappropriate funding and unavailability of critical support systems including strategies, guidelines, tools and patient safety standards remain major worries in Africa. Furthermore, understanding of the problems associated with patient safety culture is hampered by inadequate data (Wami et al., 2016).

\section{Significance of the study}

Nurses are considered the backbone of the health care and an important part of the health care team. A growing body of evidence indicated that the rate of medical errors and adverse events are associated with the perception of healthcare professionals towards safety (Salmond \& Echevarria, 2017).

During the work at Minia General Hospital, the researcher observed that nurses' staff had various problems related to patients' safety culture such as, poor infection control, improper waste management, and medication errors. Highly technologically advanced environment add to the complexity of care, together with communication barriers, and carrying out a great many activities per patient and per day, considered to be a great challenge for health care providers. So the researcher decides to assess perceptions of staff nurses about patient safety culture.

Because nurses are the frontline risk managers caring for patients 24 hours a day, investigating and analyzing their patient safety culture, perception of safety control, and patient safety management activities are necessary to prevent medical errors and improve patient safety (Jang et al., 2017).

Developing countries have been encouraged by the joint global initiative of the WHO and the World Alliance for Patient Safety (WAPS) to launch a concerted effort which will help in the assessment of the magnitude of the problem. One of the studies that evaluated patient safety in Arab countries has used the Patient Safety Friendly Hospital Initiative (PSFHI) standards. Ministries of health in seven developing countries have been assessed using the PSFHI which included Egypt, Jordan, Morocco, Pakistan, Sudan, Tunisia and Yemen. One hospital in each country was assessed against the PSFHI standards (Shu et al., 2015) so, the assessment of staff nurses perceptions about patient safety culture is important.

\section{Aim of the study:}

The aim of the current study is to assess perceptions of staff nurses about patient safety culture at Minia General Hospital

\section{Research questions}

What is perception of staff nurses about patient safety culture at General Hospital?

Is there a relation between perceptions of staff nurses about patient safety culture at General Hospital and their personal data?

\section{Subjects and Methods \\ Research Design}

Descriptive cross sectional research design was used to achieve the aim of the current study.
Setting

The study was conducted at Minia General Hospital, at Minia city, Egypt. Minia General Hospital composed from three building; first building consisted of three floors (the administration in the ground floor, second and third floor contain different departments such as (Medical, Surgical, Obstetric, Gynecological, Burn and Delivery Room). The second building consist of three floors (Emergency Department in the ground floor; $\mathrm{CCU}$ is in the second floor; and Neonatal Intensive Care Unit (NICU) and pediatric department are in the third floor). The third building contains dialysis units. This hospital is generalized in caring for all specialties; it provides free and economic services through different departments and units.

\section{Subjects}

Study subjects were included all available staff nurses during data collection at Minia General Hospital. The study subjects were consisted from all units of hospital (no. $=280)$ and divided as follows:

\begin{tabular}{|lc}
\hline Unit & No of staff member \\
\hline Outpatient & 23 \\
Ortho & 10 \\
General medical & 5 \\
\hline Ear, Nose and throat & 2 \\
\hline Urology & 3 \\
Burn & 11 \\
\hline Surgical units & 40 \\
\hline Genecology & 14 \\
\hline Operating room & 16 \\
\hline Dialysis & 30 \\
Toxicology & 6 \\
\hline \multicolumn{1}{c}{ Pediatric } & 12 \\
\hline Neonatal intensive care unit & 32 \\
\hline Intensive care unit & 37 \\
Emergency & 39 \\
\hline Total & 280 \\
\hline
\end{tabular}

\section{Data Collection Tool}

Data was collected by using one tool that comprised of two parts as follows:

\section{Part I: personal data sheet}

It was used to collect data about the staff nurses data. It included items related to age, gender, marital status, qualification, years of experience in the nursing field, department, and shift of working.

\section{Part II: Staff Nurses Perception about Patient Safety Culture}

The tool developed by the Agency for Healthcare Research and Quality (AHRQ) (2016) in the USA to measure patient safety culture. It consisted of 42 items grouped into 12 dimensions as follows: teamwork within units (4 items) ,supervisor/management\& actions promoting patient safety (4 items), organizational learning (3 items), management support for patient safety ( 3 items), overall perception of patient safety (4 items), feedback\& communication about error (3 items), communication openness (3 items), frequency of events reported ( 3 items), teamwork across units (4 items), staffing (4 items) handoffs \& transitions (4 items) and non-punitive response to errors (3 items).

Each item will be measure using five point Likert scale ranged as "strongly disagree $=1$ to strongly agree $=5$ ". There were (15 items) negatively statements which have 
reversed score as follows "Strongly disagree $=5$, to strongly agree $=1 "$. The total scoring system of this part were distributed as low level of patient safety perception if staff nurses had score (42 to 98); moderate level of patient safety perception if staff nurses had score (99 to 154); and high level of patient safety perception if staff nurses had score (155 to 210).

\section{Validity of the tool:}

Tool was tested for the content validity by a jury of (5) experts in the field of Nursing Administration and necessary modifications were done. The jury composed of one Professor and one Assistant Professor from Faculty of Nursing, Minia University; and three professors from Faculty of Nursing Assuit University. Each of the expert panel was asked to assess the instruments for content coverage, clarity, wording, length, format, and overall appearance. No necessary modification was done from jury panel.

\section{Reliability of the tool:}

Reliability of the tool was performed to confirm its consistency. The internal consistency measured to identify the extent to which the items of the tool measured the same concept and correlate with each other by Cronbach's alpha test that revealed good internal reliability for the tool; and it was $(0.88)$ for the tool.

\section{Pilot Study}

A pilot study was conducted on $10 \%$ of participants (28 nurses' staff) to ascertain the clarity, comprehensiveness, and applicability of the tool as well as to estimate the appropriate time required to fill the questionnaire. Based on pilot study there was no modification done, and it was added to final results.

\section{Data Collection Procedure}

An official letter was granted from the Nursing Faculty Dean at Minia University, Ethical committee Nursing Faculty at Minia University, and Ministry of Health - Egypt, Written approvals were obtained from the Director of Minia General Hospital, and director of nursing in Minia
General Hospital, Minia city after explaining the purpose of the study.

The questionnaire was distributed to all staff nurses after explaining the purpose of the study and process of data collection. Tool was administered directly and supervised by the researcher with the assistance of head nurse of each unit.

The researcher distributed that questionnaire for staff nurses through morning, evening, and night shift during the working days.

Participants were given from 20 minute to 30 minutes to answer the tool. They were allowed to discuss with researcher any item that needs more clarification.

The data collection was performed from staff nurses of Minia General Hospital, at Minia City during the period of 3 months from the beginning of March 2021 to the end of May 2021.

\section{Administrative design}

A written initial approval was obtained from the Research Ethics Committee of the Faculty of Nursing, Minia University. An official letter was granted from Faculty Dean, Ministry Of Health and director of Minia General Hospital, at Minia City.

\section{Ethical Consideration}

The staff nurses were informed that the participation in this study was voluntary and they can have no harm if they do not participate in the study. Oral consents were obtained from staff nurses after explaining the nature and benefits of the study. The participants' name was not appearing on the sheets for the purpose of anonymity and confidentiality.

\section{Data statistical analysis}

Data entry was done using compatible personal computer. Statistical analysis done by using statistical package of social science (SPSS, IBM) version 25 and excel for figures. The content of tool was analyzed, categorized, and then coded. Data were presented using descriptive statistics in the form of frequencies and percentages for qualitative variables and; means and standard deviations for quantitative variables. Statistical significance used at $\mathrm{P}$ value $<0.05$. Fisher- exact test was used to detect the relations.

\section{Results}

Table (1): Distribution of the staff nurses' personal data (no. $=280$ )

\begin{tabular}{|c|c|c|}
\hline Characteristics & $($ no. $=280$ & $\%$ \\
\hline \multicolumn{3}{|l|}{ Age } \\
\hline - $22-32 \mathrm{yrs}$ & 191 & 68.2 \\
\hline $33-43 \mathrm{yrs}$ & 52 & 18.6 \\
\hline $44-54 \mathrm{yrs}$ & 25 & 8.9 \\
\hline$\geq 55 \mathrm{yrs}$ & 12 & 4.3 \\
\hline \multicolumn{3}{|c|}{ Mean + SD $=31.77 \pm 8.725$} \\
\hline \multicolumn{3}{|l|}{ Marital statues } \\
\hline - $\quad$ Single & 70 & 25 \\
\hline - $\quad$ Married & 200 & 71.4 \\
\hline Widow & 10 & 3.6 \\
\hline \multicolumn{3}{|l|}{ Qualification } \\
\hline - $\quad$ Diploma & 110 & 39.3 \\
\hline - $\quad$ Technical & 96 & 34.3 \\
\hline - Bachelor & 74 & 26.4 \\
\hline \multicolumn{3}{|l|}{ Years of experience } \\
\hline - $1-10 \mathrm{yrs}$ & 188 & 67.1 \\
\hline - $\quad 11-20 y r s$ & 46 & 16.4 \\
\hline - $\quad 21-30 \mathrm{yrs}$ & 37 & 13.2 \\
\hline - $\quad<31 \mathrm{yrs}$ & 9 & 3.2 \\
\hline
\end{tabular}


Table (1) shows the personal data of the staff nurses, in relation to age there are $(68.2 \%)$ have (22-23) years old with mean age score $(31.77 \pm 87.25)$. Regarding marital status there are (71.4\%) married; and for educational qualification there are $(39.3 \%)$ of staff nurses have diploma degree. For years of experiences, there are (67.1\%) have (1- 10) years of experiences.

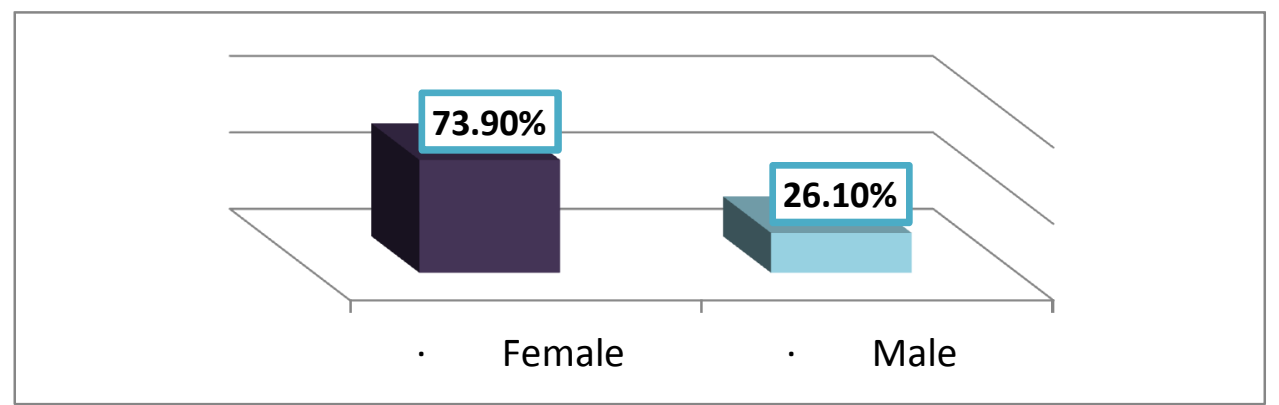

Figure (1): Distribution of the staff nurses' regarding their gender (no.=280)

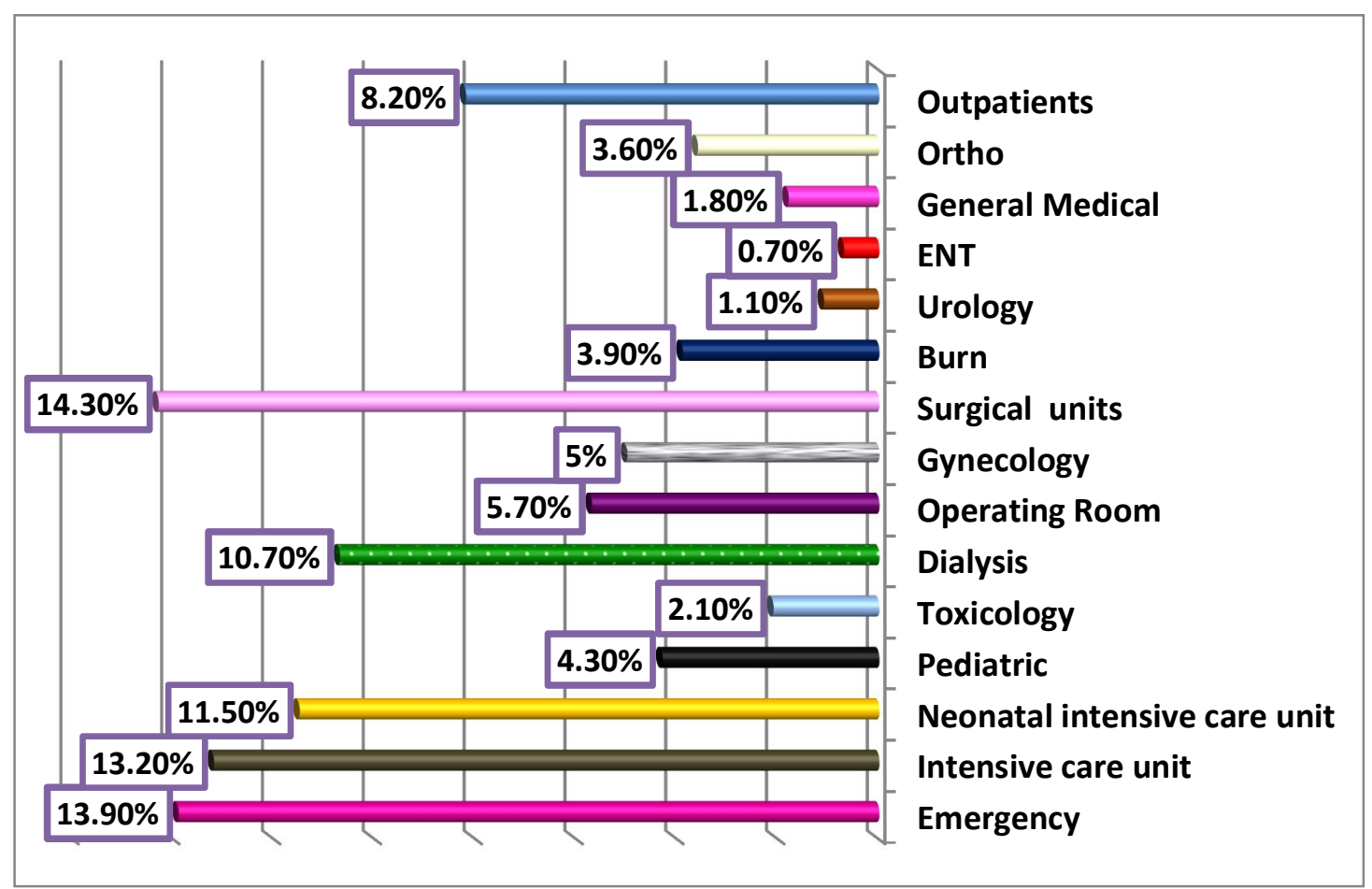

Figure (2): Distribution of the staff nurses' regarding their departments $(\mathrm{no}=\mathbf{2 8 0})$

Figure (1) shows that there are (73.9\%) of staff nurses are female. Regarding departments, figure (2) shows that there are $(14.3 \%, 13.9 \%$, and $13.2 \%)$ of staff nurses work in surgical units, emergency and intensive care unit respectively

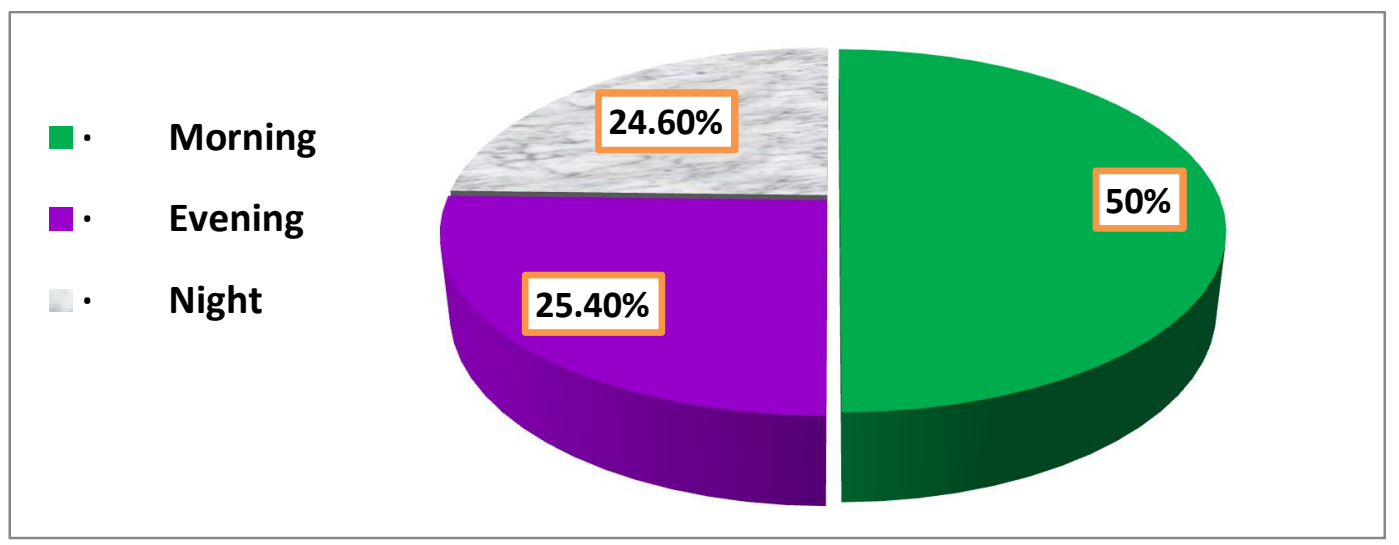

Figure (3): Distribution of the staff nurses' regarding their shift at $(\mathrm{no}=\mathbf{2 8 0})$

Speaking about shift, figure (3) shows that there are (50\%) of staff nurses work in the morning shift. 
Minia Scientific Nursing Journal (Print - ISSN 2537-012X) (Online - ISSN 2785-9797) Vol. (10) No. (1) December 2021

Table (2) Levels of nurses staff perceptions regarding patient safety culture dimensions (no=280)

\begin{tabular}{|c|c|c|c|c|c|c|}
\hline \multirow{3}{*}{ Patient safety culture Dimensions } & \multicolumn{6}{|c|}{ Staff nurses $(n=280)$} \\
\hline & \multicolumn{2}{|c|}{ Low } & \multicolumn{2}{|c|}{ Moderate } & \multicolumn{2}{|c|}{ High } \\
\hline & no. & $\%$ & no. & $\%$ & no. & $\%$ \\
\hline 1- Frequency of event reporting & 37 & $13.2 \%$ & 108 & $38.6 \%$ & 135 & $48.2 \%$ \\
\hline 3- Supervisor $\backslash$ manager expectations and actions promoting patient safety & 69 & $24.6 \%$ & 141 & $50.4 \%$ & 70 & $25 \%$ \\
\hline 4- Organizational learning continuous improvement & 39 & $13.9 \%$ & 114 & $40.7 \%$ & 127 & $45.4 \%$ \\
\hline 5- Teamwork within units & 42 & $15 \%$ & 109 & $38.9 \%$ & 129 & $46.1 \%$ \\
\hline 6- Communication openness & 40 & $14.3 \%$ & 149 & $53.2 \%$ & 91 & $32.5 \%$ \\
\hline 7-Feedback and communication about error & 25 & $8.9 \%$ & 104 & $37.2 \%$ & 151 & $53.9 \%$ \\
\hline 8- Non-punitive response To error & 62 & $22.2 \%$ & 123 & $43.9 \%$ & 95 & $33.9 \%$ \\
\hline 9- Staffing & 43 & $15.3 \%$ & 159 & $56.8 \%$ & 78 & $27.9 \%$ \\
\hline 10-Hospital management support for patient safety & 47 & $16.8 \%$ & 131 & $46.8 \%$ & 102 & $36.4 \%$ \\
\hline 11- Teamwork across hospital units & 48 & $17.2 \%$ & 149 & $53.2 \%$ & 83 & $29.6 \%$ \\
\hline 12-Hospital handoffs and transitions & 80 & $28.6 \%$ & 112 & $40 \%$ & 88 & $31.4 \%$ \\
\hline
\end{tabular}

Table (2) displays that the staff nurses have high total scores regarding patient safety culture for the dimensions (feedback and communication about error (53.3\%) followed by frequency of event reporting (48.2\%), then teamwork within units (46.1\%) and then organizational learning continuous improvement $(45.4 \%)$. While; the staff nurses have moderate response for the rest of patient safety culture dimensions.

Also, this table shows that have low score in "high response" from staff nurses perception are supervisor $\backslash$ manager expectations and actions promoting patient safety (25\%), overall perceptions of patient safety (26.5\%), staffing (27.9\%) and teamwork across hospital units $(29.6 \%)$

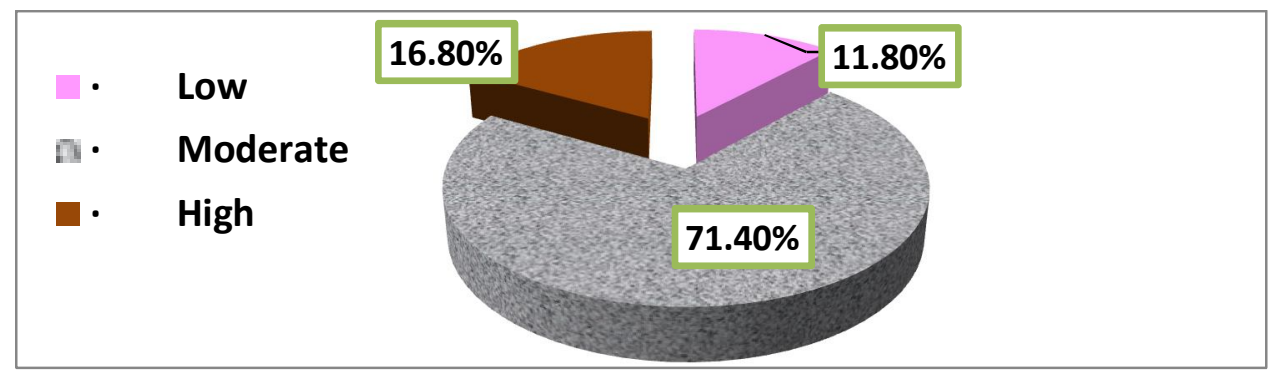

Figure (4) Percentage distribution of staff nurses total scores regarding patient safety culture (no=280)

Figure (4) displays that the $(71.4 \%)$ of staff nurses have moderate total scores regarding patient safety culture, as well there are $(16.8 \%)$ of them have high responses, and only $(11.8 \%)$ have low perception regarding patient safety culture.

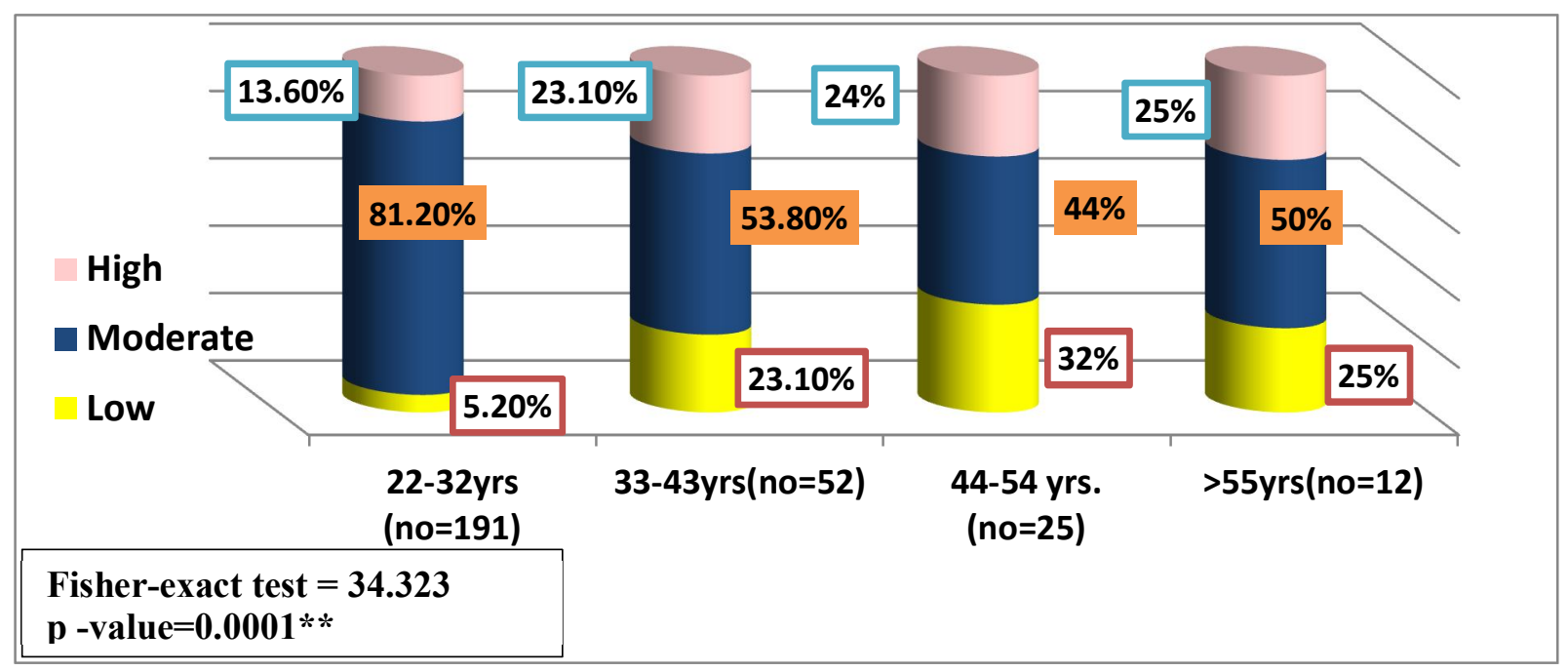

Figure (5) Relation between staff nurses' age and total score of patient safety culture (no=280)

Figure (5) displays that there are highly statistical significant relations between staff nurses age and their total score regarding the patient safety culture in favor to the staff nurses with age (22-32 years) there are (81.20\%) of them have moderate score; and there are $(25 \%)$ of staff nurses with age $(>55$ years $)$ have high score to patient safety culture with p-value $(=0.0001)$. 


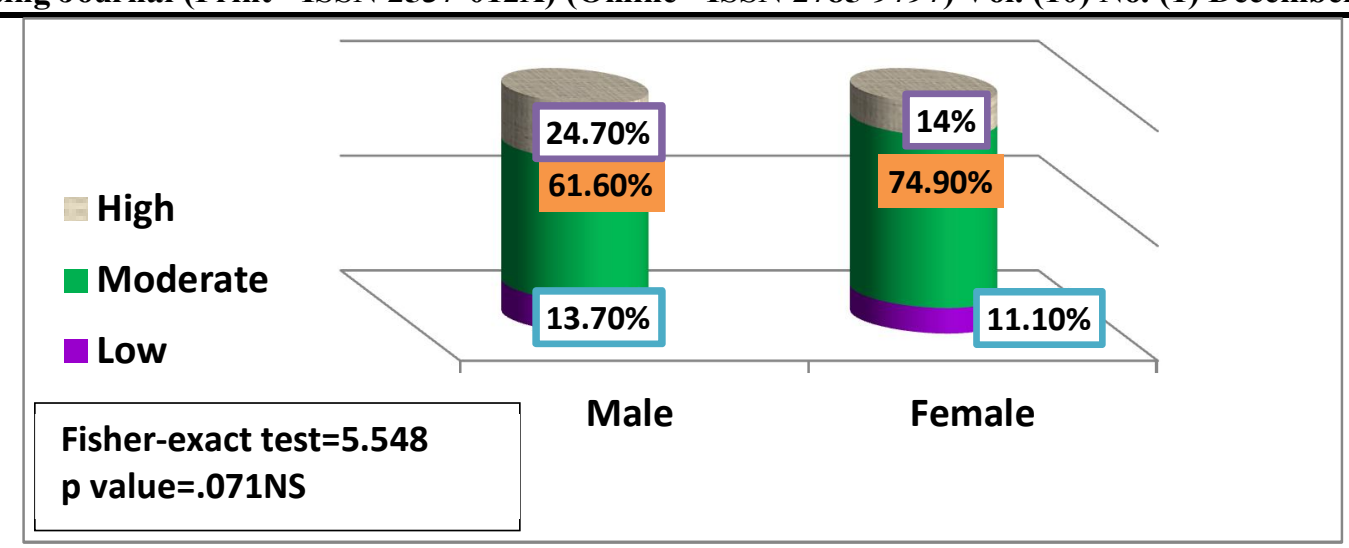

Figure (6) Relation between staff nurses' gender and total score of patient safety culture (no=280)

Figure (6) displays that there is no statistical significant relation between staff nurses gender and their total score regarding the patient safety culture with p-value $(=0.071)$

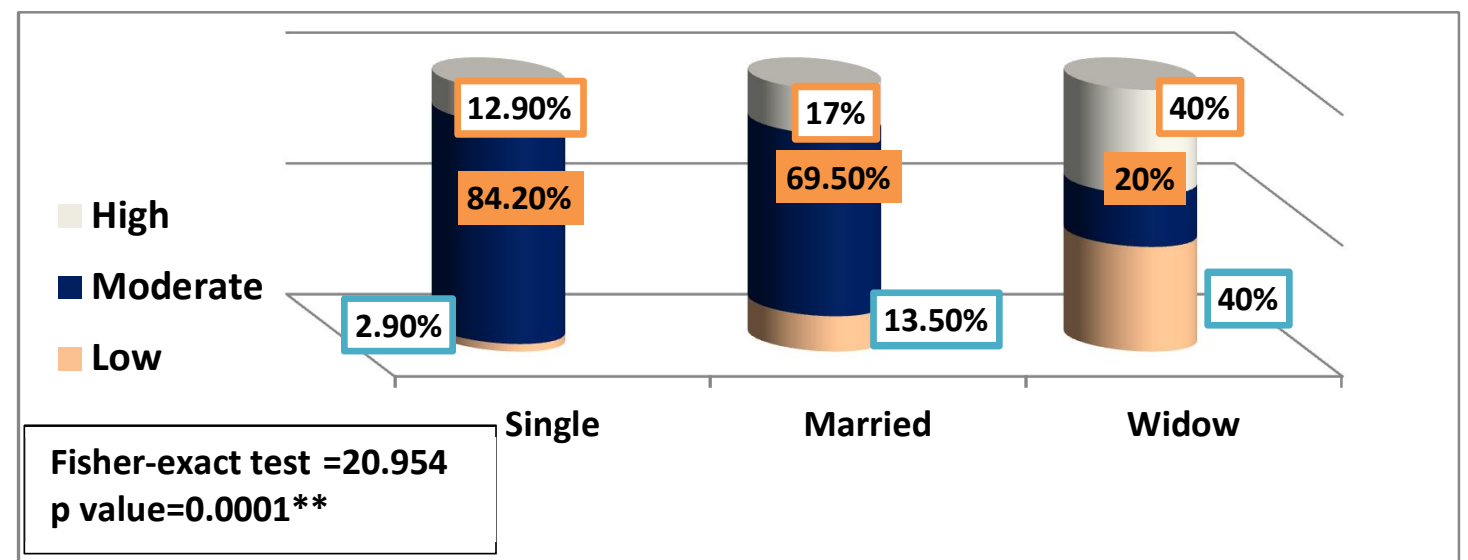

Figure (7) Relation between staff nurses' marital statues and total score of patient safety culture (no. $=\mathbf{2 8 0})$

Figure (7) displays that there are highly statistical significant relations between staff nurses marital status and their total score regarding the patient safety culture in favor to the staff nurses who are single as $(84.2 \%)$ of them have moderate score; and there are $(40 \%)$ of widow have high score with p-value $(=0.0001)$.

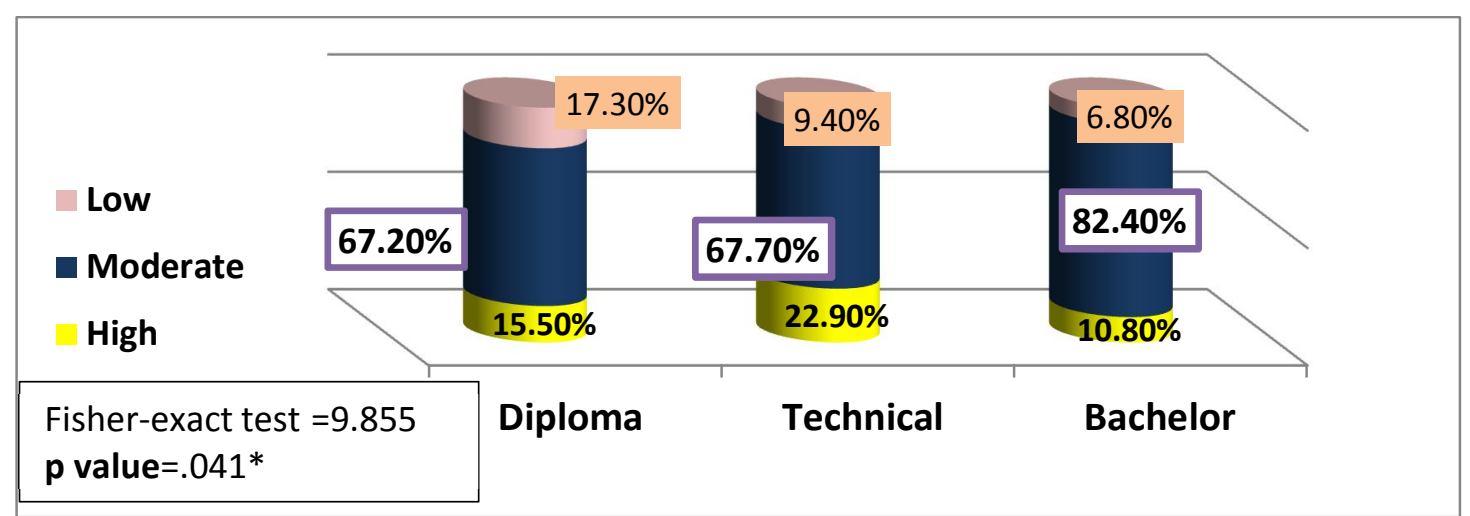

Figure (8) Relation between staff nurses' educational qualification and total score of patient safety culture (no=280)

Figure (8) shows that there are statistical significant relations between staff nurses educational qualifications and their total score regarding the patient safety culture in favor to the staff nurses who have bachelor degree in which there are (82.4\%) of them have moderate score and $(10.8 \%)$ of them have high total score; as well as there are $(22.9 \%)$ of staff nurses who had technical degree have high total score with p-value $(=0.041)$ 


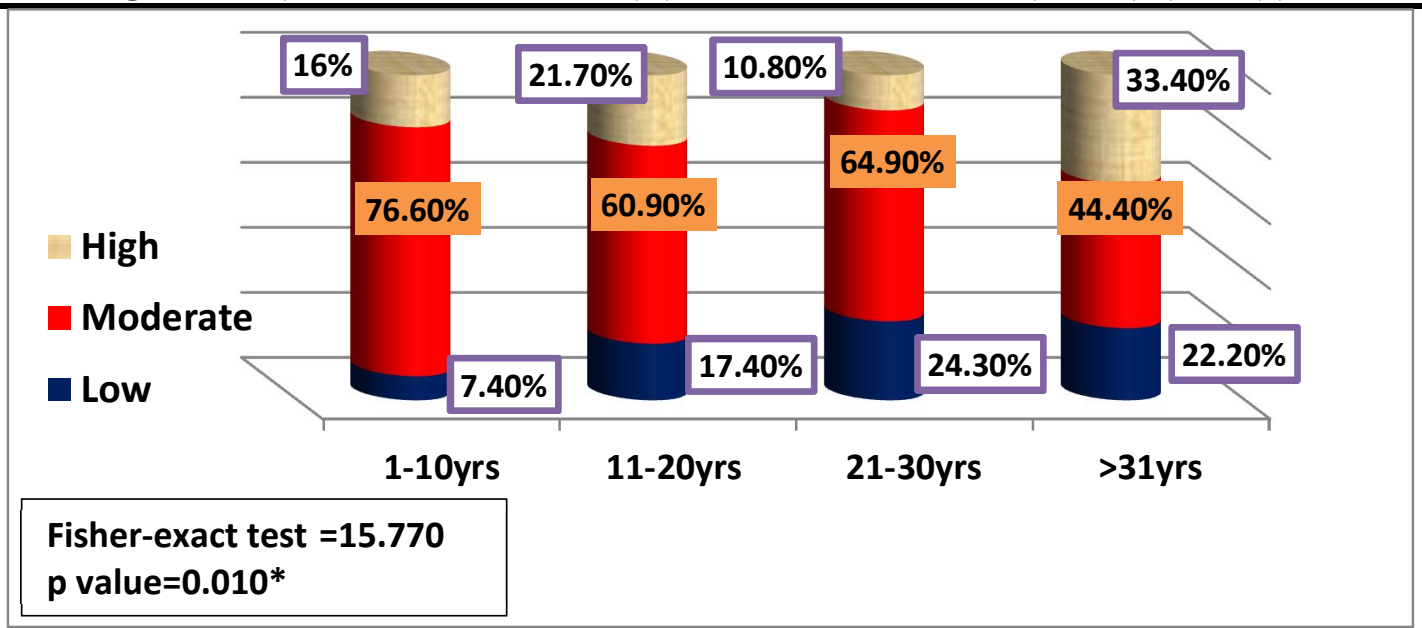

Figure (9) Relation between staff nurse's years of experience and total patient safety culture $(\mathbf{n o}=\mathbf{2 8 0})$

Figure (9) shows that there are statistical significant relations between staff nurses years of experiences and their total score regarding the patient safety culture in favor to the staff nurses who have (1 to 10) years of experiences as (76.6\%) of them have high moderate score and there are $(33.4 \%)$ of staff nurses who have $(>31$ years) have high score with p-value $(=0.010)$

\section{Discussion:}

Safety is a critical and essential component of quality patient care. Wide range of action including performance improvement, infection control, safe use of medicines and equipment, safe clinical practice and safe environment, is needed to ensure safety in healthcare. A comprehensive multifaceted approach from all healthcare disciplines and actors considered to be a key for identifying and managing potential risks to patient safety (Muftawu\& Aldogan, 2020).

Also, patient safety is a field in the health profession in which one goal is to achieve a trustworthy healthcare delivery through the application of safety science methods. It is an attribute of healthcare system aim at alleviating the incidence and effect of adverse events (Alotaibi\& Federico, 2017).

To improve healthcare quality, there is the need to establish a culture of safety which requires an understanding of the values, beliefs, and norms about what is important in an organization, and what attitudes and behaviors related to patient safety are expected and appropriate (Al Doweri, et al., 2015).

The current study showed about personal data of staff nurses; in relation to age there were more than two thirds had (22-23) years old with mean age score $(31.77+87.25)$. Regarding marital status, there were more than two third of staff nurses married, and highest percentage of staff nurses had diploma degree. For years of experiences, there were more than two third of staff nurses had (1-10) years of experiences.

Also, the current study presented that near to three quarters of staff nurses were female. Regarding departments, the highest percentage among staff nurses were in surgical units, emergency and intensive care unit. Speaking about shift, there were half of staff nurses worked in the morning shift.

Regarding the patient safety culture dimensions, it was observed from current findings that the highest percentage of staff nurses had high total scores regarding patient safety culture for the dimensions "feedback and communication about error", followed by "frequency of event reporting" then "teamwork within units" and "organizational learning continuous improvement". While the rest of other dimensions; the highest percentage of staff nurses had "moderate responses". Also, the lowest dimensions that have low score in "high response" from staff nurses perception

$P$ a g e $\mid 74$ were supervisor $\backslash$ manager expectations and actions promoting patient safety; overall perceptions of patient safety; staffing; and teamwork across hospital units.

These results may be due to many reasons such as; the relation the staff nurses had in work with their supervisors; they are given feedback about changes that should be put into place based on event reports; they are informed from their supervisors the errors that happen in their units and work with each other to solve these errors.

Also, the staff nurses had high responses for the frequency of reporting errors due to their perception about the importance of reporting errors even if the repots will be a punishment to them as they agreed that when a mistake is made, but is caught and corrected before affecting the patient, it should be reported; they agreed that when a mistake is made and cannot have harm the patient it also should be reported.

Also, the staff nurses had high responses for the teamwork within units in which they perceived and aware that the spirit of teamwork is crucial and needed for patient safety and improve quality of care. Also, this result may attributed that staff nurses had positive for the helpmate they have; they have more support and aid in their units work; they agreed that when a lot of work needs to be done quickly, they agreed that working together as a team encourage and help them to get the work done quickly; they receive and give respect to each other; and they provide help and support to the other staff nurses in the one unit when there was a workload in the work or when there was an emergency.

Also, the staff nurses had high responses for the organizational learning - continuous improvement; in which they have high agreement that continuous improvement for their performance is crucial for patient care and patient safety. This result may be explained that staff nurses were actively doing things in order to improve patient care and safety; they learn from their mistakes positively to improve their performance and their supervisors continuous make evaluation of their performance.

These results are in line with Alahmadi (2010) in Saudi Arabia, who had a hospital survey on patient's safety culture questionnaire was distributed in 13 general hospitals in Riyadh City, to 223 health professionals including nurses, technicians, managers and medical staff. The study result showed that the areas of strength for most hospitals were: organizations learning/continuous improvement, teamwork

Eman S., et al 
within units, and feedback and communication about errors. The study concluded that leadership is a critical element to the effectiveness of patient's safety initiatives and response to errors is an important determinant of safety culture in healthcare organizations.

Also, these results are similar to the findings in Turkey with Ugurluoglu et al., (2012) in Turkey; Nordin et al., (2013) in Sweden; as well as El -Jardali et al., (2014) in Riyadh; and in Kuwait with Ghobash et al., (2014) in which all of these studies mentioned from their findings about patient safety culture perception that the dimension of Teamwork has a great potential for preventing medical error.

Also Cheng et al., (2019) results indicated that the mean scores for all Safety Attitude Questionnaire in Chinese dimensions which were teamwork climate, safety climate, job satisfaction, perception of management, and working conditions with the exception of the working-conditions domain for dental healthcare workers reached a score of 75 , which is considered to indicate a positive attitude.

Moreover, this is in agreement with Muftawu and Aldogan, (2020) who had a study for measuring patient safety culture from healthcare team at a teaching hospital in Ghana and agreed that teamwork within units was the dimension with the highest positive composite score. And this suggests that staff in the hospital support and treat one another with respect and support each other.

Furthermore Lee and Quinn, (2020) in their studies about patient safety outcomes in East Asia by the literature review; they displayed that among safety culture aspects, feedback and communication, frequency of event reporting, teamwork within units, and managers' support for patient safety were most significantly related to patient safety outcomes.

Also Tili et al., (2020) agreed with current study results in which the dimension of "teamwork within units" had the highest score (70.6\%); and the dimension "staffing" $(34.76 \%)$ and "non-punitive response to errors" (36.5\%) had lowest score. While their study results disagreed with current study in which the dimension "frequency of event reporting" had low score in their study (27.6\%).

Moreover, the current study results is not congruent with Alahmadi, (2010) who mentioned that the areas with potential for improvement for most hospitals were underreporting of events, non-punitive response to error, staffing, and teamwork across hospital units.

Also, these results are not in line with the studies of Bodur and Filiz (2009); Ugurluoglu et al., (2012); Barrow, (2012); and Amarapathy, et al., (2013) who agreed in their studies that the frequency of event reporting dimension had the lowest score. This suggests that staff feel reluctant to report errors when they occur. Moreover Abdelrahman and Mohamed, (2017) stated from their study findings that the highest mean scores among Minia internship nursing students regarding patient safety culture were "the hospital work area /unit", "your supervisor/ manager communication", and "patient safety at your hospital".

In addition regarding total sore of patient safety culture, the current study revealed that the highest percentage of staff nurses had moderate total scores regarding patient safety culture, as well there were one-sixth of them had high responses, and only (11.8\%) had low perception regarding patient safety culture.

These results may attributed that the staff nurses at Minia General Hospital perceived the importance of patient safety culture but they need more training on maintaining safety, as well as they still in a need for realizing that patient safety culture refers to the management as well as their values, beliefs, and norms. They need to consider what is important in a health system, how health care staffs are expected to behave, what attitudes and actions are appropriate and inappropriate, and what processes and procedures are rewarded and punished with regard to patient safety.

This result is in line with Alahmadi, (2010) results who showed that the overall patient's safety grade was rated as excellent or very good by $60 \%$ of respondents, acceptable by $33 \%$ and failing or poor by $7 \%$. Also, Amarapathy et al., (2013) who a study titled "Factors Affecting Patient Safety Culture in a Tertiary Care Hospital in Sri Lanka" revealed that there is a positive response towards patient safety culture within the organization.

Moreover, Nordin et al., (2013) in their study about "Swedish Hospital Survey on Patient Safety CulturePsychometric properties and health care staff's perception" agreed that the safety was graded as very good by $58.9 \%$ of the respondents. Muftawu and Aldogan (2020) in their study displayed that more than half of respondents perceived that overall response of the 12 dimensions of patient safety culture was positive.

Regarding the relations; the current study findings displayed that there were statistically significant relations between staff nurses total score regarding the patient safety culture and their age, marital status, educational qualification, and years of experiences. While the current study showed that there was no statistically significant relation between staff nurses gender and their total score regarding the patient safety culture.

In relation to age, there were highly statistical significant relations between staff nurses age and their total score regarding the patient safety culture in favor to the majority of staff nurses with age (22-32 years) had moderate score, and one quarter of staff nurses with age ( $>55$ years) had high score. For the marital status; the majority of staff nurses who are single had moderate score; and more than one third of widow had high score.

Regarding educational qualifications; the majority of staff nurses who had bachelor degree had moderate score as well as near to one quarter of staff nurses who had technical degree had high total score; for years of experiences; more than three quarter of staff nurses who have (1 to 10) years of experiences had high moderate score and there were one third of staff nurses who have ( $>31$ years) had high score.

Of great concern and respect to all staff nurses; these results may attributed that the staff nurses who are young had moderate score because they are more aware of the patient safety culture than other staff nurses due to their age. Also this may be due to their new graduation and knowledge they still remember from their studies. Also, the youngest staff nurses are more enthusiastic than other for providing high quality of care to maintain patient safety. However, the older staff nurses had high score due to their experiences and work with patients.

In addition the staff nurses who had a bachelor or technical degree have more realization regarding patient safety culture due to their academic studies in Faculty of Nursing or Technical Institute of Nursing; they had been more than one time to study the patient safety in different curriculum during their four academic years. They learned from their faculty/ institute staff member the role model of maintaining patient 
safety during their practical training in hospitals. The single staff nurses are the youngest staff; and this means that the single staff nurses had more awareness about patient safety culture.

As well as, it is a fact that the youngest staff nurses age had the lowest years of experiences (1 to 10 years); thus they were more aware about patient safety culture than the other staff nurses. The more years of experiences among staff nurses as they are older, the more wisdom and practice to foster and improve the patient safety culture.

These results are matched with the results of Abdou and Saber, (2011) whose stated that, there were statistically positive significant differences among nurses regarding their perception for all safety culture dimensions specifically with shift $(p=0.001)$, age group $(p=0.022)$ and educational qualification $(\mathrm{p}=0.043)$.

Furthermore, these results are congruent with Elsehrawy et al., (2015) who revealed from their study findings that there were statistically positive significant correlations between the response of the nurses working in medical units regarding patient safety culture with their age as $(p=0.013)$ and years of experience as $(p=0.009)$.

As well as, these results agreed with Ege et al., (2019) who indicated that the patient safety culture of nurses was acceptable and correlated with their education levels. These results are congruent with Ibrahim and Abo-Habieb, (2020) in which they mentioned in their study that there was statistically significant relationship between nurses' patient safety culture and their educational level.

While; these results was contradicting with Ahmed et al., (2011) who concluded that the correlation of staff nurses' age and their perception of patient safety culture showed significant weak negative correlation. Also, these results were incongruent with Tabrizchi and Sedaghat, (2012) as they stated that there were no relationships between age and working years in their present center or total work records and their score about patient safety culture.

In addition, these were conversely with the study of Ammouri et al., (2015) reported that the nurses who had more years of experience had more perception of patient safety culture, and the other nurses' characteristics such as gender, age, educational degree had no significant relationship with the nurses' perception of patient safety culture.

Also, the current findings disagreed with Abdelrahman and Mohamed, (2017) who stated that there were no statistically significant differences between personal characteristics and all patient safety culture factors. Also, Abu-El-Noor et al., (2019) who found that there were no statistically significant differences in the overall culture of patient safety with age, education, and experience of nurses from four governmental hospitals in the Gaza Strip, Palestine.

Conclusions

This study assessed the perception of patient safety culture at a Minia General Hospital at Minia; and the results indicated that the overall perception of staff nurses regarding patient safety culture in the hospital were moderate. The highest staff nurses high responses were for the dimensions "feedback and communication about error", followed by "frequency of event reporting" then "teamwork within units" and "organizational learning continuous improvement". While, the staff nurses had low responses about patient safety culture perception were for the dimensions "supervisor $।$ manager expectations and actions promoting patient safety"; "overall perceptions of patient safety"; "staffing'; and "teamwork across hospital units". Thus patient safety should be made a top priority for management and frontline staff in the hospital.

\section{Recommendations}

- Nurses should be encouraged to participate and foster the patient safety activities and communication channels in order to maintain safety regulation.

- Administrative authorities and leaders should develop measurable standards for patient safety system. This can be achieved through initiated and supported an effective safety culture assessment among all working nurses.

- Staff development programs are needed for all nurses to understand the values, beliefs, and norms about what is important in an organization and what attitudes and behaviors related to patient safety are expected and appropriate for achieving a culture of safety.

- Nurse Managers should maintain work environment with adequate staffing, and resources, teamwork to avoid patient care errors and missing care.

\section{References}

(1) Abdelrahman, S. M., \& Mohamed, F. R. (2017). Patient safety culture as perceived by internship nursing students.

(2) Abdou, A. H. \& Saber, K.M. (2011). A Baseline Assessment of Patient Safety Culture among Nurses at Student University Hospital, World Journal of Medical Sciences 6 (1) (2011), IDOSI Publications.

(3) Abu-El-Noor, N. I., Abu-El-Noor, M. K., Abuowda, Y. Z., Alfaqawi, M., \& Böttcher, B. (2019). Patient safety culture among nurses working in Palestinian governmental hospital: a pathway to a new policy. BMC Health Services Research, 19.550 (1)

(4) Agency for Healthcare Research and Quality (AHRQ). AHRQ Hospital Survey on Patient Safety Culture: User $\square \mathrm{s}$ Guide. 2016. Available at http://www.ahrq.gov/professionals/quality-patientsafety/ patient safety culture/hospital/index.html

(5) Ahmed G.N., Adam M.S. \& Abd Almoniem I.I. (2011). Patient safety: Assessing nurses' perception and developing an improvement plan, life science journal, may 8 (2): 53.

(6) Al Doweri, H.F. Al Raoush, A.T., Alkhatib, A.J. \& Batiha, M.A. (2015). Patient's Safety Culture: Principles and Applications: Review Article. European Scientific Journal May 2015 edition vol.11, No.15 ISSN: 1857 - 7881 (Print) e - ISSN 1857- 7431.

(7) Al- Lawati, M.H., Short, S.D., Abdulhadi, N.N., Panchatacharam, S.M.\& Dennis, S. (2019). Assessment of patient safety culture in primary health care in Muscat, Oman: a questionnaire -based survey. BMC Family Practice; 20(50):1-8.

(8) Alahmadi HA (2010). Assessment of patient's safety culture in Saudi Arabian hospitals. Qual Saf Health Care., 19(5):e17.

(9) Almutairi, K. M., Al Helih, E. M., Moussa, M., Boshaiqah, A. E., Saleh Alajilan, A., Vinluan, J. M., \& Almutairi, A. (2015). Awareness, attitudes, and practices related to coronavirus pandemic among public in Saudi Arabia. Family \& community health, 38(4), 332-340.

(10) Alotaibi, Y.K. \& Federico, F. (2017). The impact of health information technology on patient safety. Saudi Med J.; 38(12): 1173-1180.

(11) Amarapathy, M., Sridharan, S., Perera, R. \& Handa, Y. (2013). Factors affecting patient safety culture in a tertiary 
care hospital in Sri Lanka. Int J Sci Technol Res; 2: 173180.

(12) Ammouri, A. A., Tailakh, A. K., Muliira, J. K., Geethakrishnan, R., \& Al Kindi, S. N. (2015). Patient safety culture among nurses. International Nursing Review, 62(1), 102-110. https://doi.org/10.1111/inr.12159.

(13) Bodur, S., \& Filiz, E. (2009). A survey on patient safety culture in primary healthcare services in Turkey. International Journal for Quality in Health Care, 21(5), 348-355.

(14) Barrow M. (2012). Measuring the current patient safety culture in the Gambian Public Hospitals. Taipei Medical University. Cited from http://ibir.tmu.edu.tw/bitstream/987654321/46092/2/Mom odouBarrow.pdf. Accessed 31 August 2021).

(15) Cheng, H.C., Yen, A.M. \& Lee, Y. (2019). Factors affecting patient safety culture among dental healthcare workers: A nationwide cross-sectional survey. Journal of Dental Sciences, 14, 263-268

(16) DiCuccio, M. H. (2015). The relationship between patient safety culture and patient outcomes: a systematic review. Journal of patient safety, 11(3), 135-142.

(17) Ege, Y., Kilic D., Yildiz E. (2019). Patient Safety Culture: Evaluating Turkish Nurses' Attitudes and Knowledge. International Journal of Caring Sciences, 12(1), 430-441.

(18) El-Jardali, F., Sheikh, F., Garcia, N. A., Jamal, D., \& Abdo, A. (2014). Patient safety culture in a large teaching hospital in Riyadh: baseline assessment, comparative analysis and opportunities for improvement. BMC health services research, 14(1), 1-15.

(19) Elmontsri, M., Almashrafi, A., Banarsee, R., \& Majeed, A. (2017). Status of patient safety culture in Arab countries: A systematic review. BMJ Open, 7(2). https://doi.org/10.1136/bmjopen-2016-013487.

(20) Elsehrawy, M. G., Gaber, H., Adam, S.M. (2015). Nurse's awareness regarding patient safety culture at Mansoura University Hospital. Mansoura Nursing Journal (MNJ); 12(1): 137-146.

(21) Ghobashi M.M., El-Ragehy, H.A. \& Mosleh, H. (2014). Assessment of patient safety culture in primary health care settings in Kuwait. Epidemiol Biostat Public Health 2014; 11: 1-9.

(22) Graban, M., \& Toussaint, J. (2018). Lean hospitals: improving quality, patient safety, and employee engagement. Productivity Press.

(23) Ibrahim, I. A. \& abo Habieb, E.E. (2020). Associations between nursing work environment, patient safety culture, and missed nursing care among staff nurses. Port Said Scientific Journal of Nursing; 7(3): 244- 263.
(24) Jang, H. E., Song, Y., \& Kang, H. Y. (2017). Nurses' Perception of Patient Safety Culture and Safety Control in Patient Safety Management Activities. Journal of Korean Academy of Nursing Administration, 23(4), 450-459.

(25) Lee, S.E. \& Quinn, B.L. (2020). Safety Culture and Patient Safety Outcomes in East Asia: A Literature Review. Western Journal of Nursing Research; 42(3) 220- 230.

(26) Muftawu, M. \& Aldogan, E.U. (2020). Measuring patient safety culture: A study at a teaching hospital in Ghana. Journal of Patient Safety and Risk Management,25(6): 250-258.

(27) Nordin A, Wilde-Larsson B, Nordstr€om G, et al. Swedish Hospital Survey on Patient Safety Culture - psychometric properties and health care staff's perception. OJN 2013; 3: 41-50.

(28) Pousette, A., Larsman, P., Eklöf, M., \& Törner, M. (2017). The relationship between patient safety climate and occupational safety climate in healthcare-A multi-level investigation. Journal of safety research, 61, 187-198.

(29) Salmond, S. W., \& Echevarria, M. (2017). Healthcare transformation and changing roles for nursing. Orthopedic nursing, 36(1), 12.

(30) Shu, Q., Cai, M., Tao, H. B., Cheng, Z. H., Chen, J., Hu, Y. H., \& Li, G. (2015). What does a hospital survey on patient safety reveal about patient safety culture of surgical units compared with that of other units? Medicine, 94(27).

(31) Tabrizchi N. \& Sedaghat M. (2012), The First Study of Patient Safety Culture in Iranian Primary Health Centers, Department of Community Medicine, Tehran University of Medical Sciences, Tehran, Iran. Acta Medica Iranica journal, 2012; 50(7): 505-510. Downloaded from http://journals.tums.ac.ir/ on Saturday, April 12, 2014.

(32) Tlili, M.A., Aouicha, W., Ben-Dhiab, M. \& Mallouli M. (2020). Assessment of nurses' patient safety culture in 30 primary health care centres in Tunisia. East Mediterr Health J; 26(11): 1347-1354.

(33) Ugurluoglu, O, Ugurluoglu, E, Payziner, PD. \& Ozatkan, Y. (2012). Patient safety culture: sample of a University Hospital in Turkey. Pakistan J Med Sci; 28: 463-467.

(34) Ulrich, B., \& Kear, T. (2014). Patient safety culture in nephrology nurse practice settings: initial findings. Nephrol Nurs J, 41(5), 459-475.

(35) Wami, S.D., Demssie, A.F., Wassie, M.M. \& Ahmed A.N. (2016). Patient safety culture and associated factors: A quantitative and qualitative study of healthcare workers' view in Jimma zone Hospitals, Southwest Ethiopia. BMC Health Serv Res.; 16: 495 (1-10).

(36) World Health Organization. (2020). Patient safety. Retrieved from www.who.int/newsroom/factsheets/detail/patient-safety 